\title{
Wing polymorphisms of Pterostichus melanarius (Coleoptera: Carabidae) (Illiger, 1978) in Alberta pulse crops
}

Saraiah Cottrell-Callbeck ${ }^{1}$, Maggie MacDonald ${ }^{1}$, Maya Evenden ${ }^{1}$

${ }^{1}$ Department of Biological Sciences, University of Alberta

\begin{abstract}
In a 6 week research project, a wing-dimorphic carabid species was studied to identify the proportions of macropterous (large functional wings) individuals and brachypterous (short, rudimentary wings) individuals from different pulse growing regions of Alberta. Pterostichus melanarius I. (Coleoptera: Carabidae) can be short-winged (SW) due to brachyptery being a dominant gene or long-winged (LW) individuals causing macroptery. Although macroptery is a recessive trait, the $\mathrm{LW}$ morph persists through the recolonization of populations due to human disturbance. Their ability to fly facilitates their dispersal across Alberta to uncolonized areas. Samples of $P$. melanarius were captured as bycatch from pea leaf weevil, Sitona lineatus $L$. (Coleoptera: Curculionidae) pitfall traps from the East, Capital, and Central regions of Alberta. Traps were positioned on a 175 meter transect pea and faba field margins in spring and again in the fall. Captured P. melanarius were identified and separated by collection site and date and stored in $95 \%$ ethanol until measurements. The beetles from the bycatch samples were sexed using tarsal characteristics. Anterior tarsal segments of the front pair of tarsi are dilated in males and normal in females. After being identified and recorded as "M" or "F", they were mounted on a foam board with insect pins for measurement. The elytra (forewings) length and width was measured followed by measurement of their hindwings. They were classified as "SW" or "LW" depending on the functionality of their wings. Out of 440 individuals from the Capital region, $17.1 \%$ of captured P. melanarius were LW and $83.0 \%$ were SW. From the Central region $21.6 \%$ of 495 beetles were LW and $83.4 \%$ of them were SW. In the East region less P. melanarius were captured and from 94 individuals, $46.8 \%$ were LW and $53.2 \%$ were SW. Macropterous individuals are more common in the East region due to recolonization of populations whereas in the Central and Capital region the proportions of SW are much larger. In regions that have established populations of P. melanarius the proportions of SW are greater than LW.
\end{abstract}

Key words:

Pterostichus Melanarius, wing polymorphism

Cite as: Cottrell-Callbeck S., MacDonald M., and Evenden M. 2019. Wing polymorphisms of Pterostichus melanarius (Coleoptera: Carabidae)(Illiger, 1978) in Alberta pulse crops. Alberta Academic Review, Vol 2 (2) 23-24, WISEST Special Issue (non peer-reviewed), DOI 10.29173/ aar57. 
Cottrell-Callbeck et al., 2019

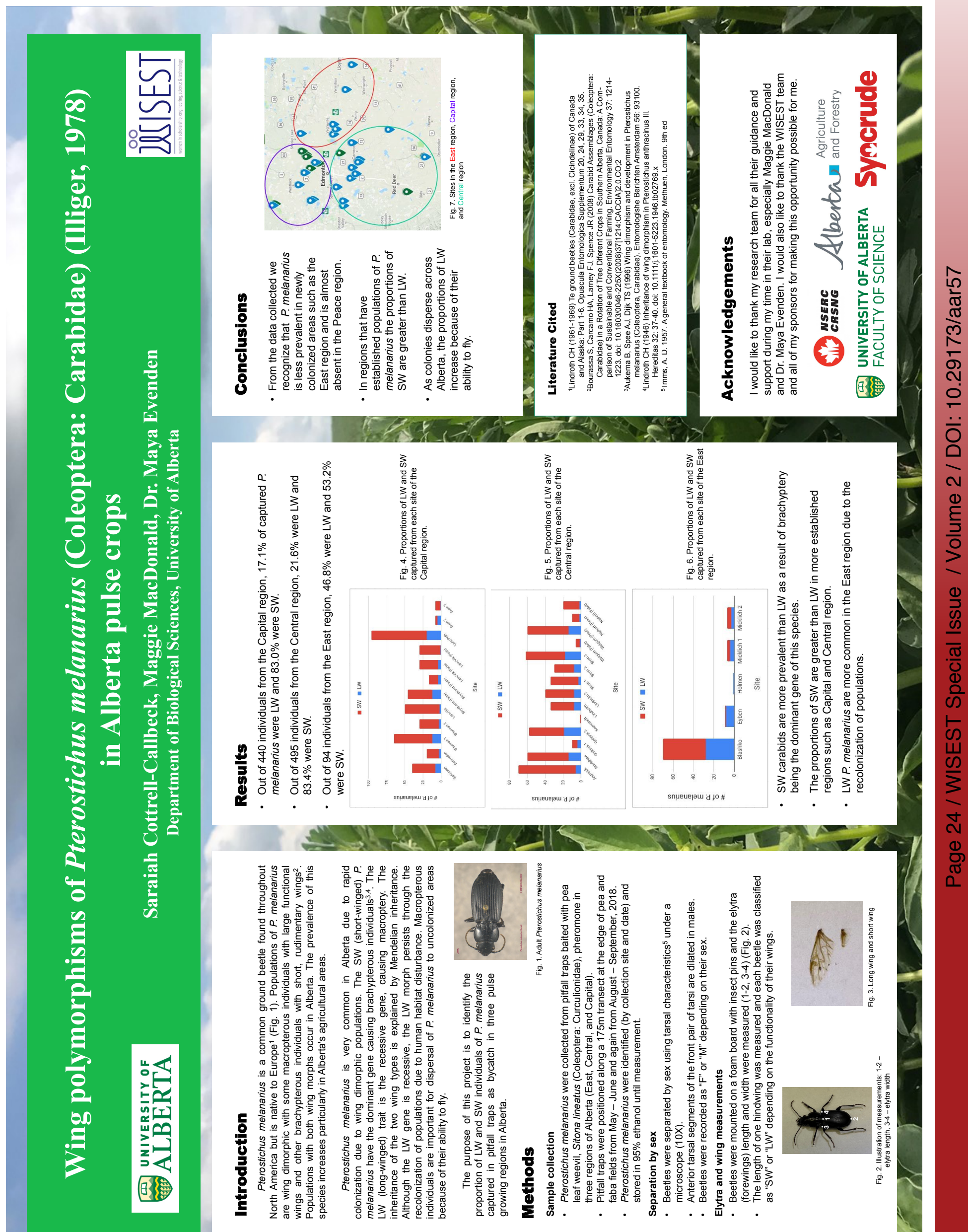

